\title{
Bid documentation in public procurement in Poland
}

Renata Kozik

Section of Technology and

Building Management, Cracow

University of Technology,

Krakow, Poland

rkozik@ztob.pk.edu.pl
Edyta Plebankiewicz

Section of Technology and

Building Management, Cracow

University of Technology,

Krakow, Poland

eplebank@izwbit.pk.edu.pl
DOI 10.5592/otmcj.2013.1.8 Research paper

\section{Keywords}

Bid documentation, Public procurement, Bidding procedure
PREPARATION OF TENDER DOCUMENTS IS THE RESPONSIBILITY OF THE ORDERER (CONTRACTING AUTHORITY). The correct description of the subject of the building works and a clear formulation of orderer's requirements have an impact on the contractor's decision to join the proceedings, as well as on the preparation of an offer. Errors in the preparation of tender documents may be the cause of many questions raised by the contractors and, as a consequence, it may become necessary to extend the process. The article briefly presents the regulations specified in Polish public procurement law relating to the requirements for contractors and the way the subject of the building works is described. Then it focuses on an analysis of questions asked by bidders during the selected procedures. Consideration will be given to the structure of questions and the factors affecting their quantity. 


\section{INTRODUCTION}

Building contractors are typically selected by means of a bidding procedure. When preparing their offer, bidders have the right to ask the orderer questions. Frequently the reasons of contractors' doubts include difficulties with understanding the orderer's intentions or establishing appropriate offer price, which is caused, for instance, by mistakes found in the documents provided by the orderer. Other reasons include the contractor's ignorance of bidding procedures or the wish to postpone the deadline for submitting bids. A large number of questions may make it necessary to supplement the documents by the orderer, subsequently leading to additional costs and prolonging the bidding procedure.

The aim of the article is to analyze bidders' questions asked in certain chosen bidding procedures, the structure of the questions and the factors influencing their number.

\section{Open tender procedure in public procurement}

Public orderers are obliged to choose a building contractor according to the rules specified in the Polish law. Since 2nd March 2004 there has been the Act of 29th January 2004 Public Procurement Law (Journal of Laws of 2010 No 113 , pos. 759 and No 161, pos. 1078 , as amended) in force.

The Act specifies both the ways of preparation and the details of the procedures of awarding contracts. In accordance with the Act, the basic procedures of awarding orders are open tender and restricted tender. The orderer may also award a contract after negotiations with announcement, competitive dialogue, negotiations without announcement, sole-source contract, price request or electronic bidding, but only in cases specified in the Act. The present article analyzes only open tender procedures, which are the most frequently employed by Polish public investors. According to Article 39 PPL, open tender is the mode of procurement in which, in response to public order, every contractor interested can bid.

When preparing bid documents for the potential bidder, the orderer should describe the subject of the contract. The contractor applying for a contract prepares a bid using the orderer's description and the specifications of the vital conditions enumerated in the contract.

In accordance with article $22 \mathrm{PPL}$, a contract may be awarded to those contractors who fulfill the following conditions.

1. They have the authorization to perform a given activity if this is required by law.

2. They have knowledge and experience.

3. They possess the relevant technical potential and resources allowing them to fulfill the contract.

4. Their economic and financial situation is safe.

To prove that the conditions mentioned above are fulfilled, the orderer may require that the contractor presents statements and documents which are specified in the relevant regulation. In a procedure for awarding a contract the orderer may require from the contractor only statements or documents necessary to conduct the procedure. These statements and documents become an element of the bid documents that the contractor provides.

In the case of any doubts regarding the documents that the orderer requires or establishing the offer price, the contractor may ask the orderer questions. The orderer must provide explanations. The questions and answers to then are then handed in to the contractors who were already given the specifications of the vital conditions of the contract, but the source of the questions is not revealed. The orderer may also call a meeting of all contractors in order to clarify any doubts concerning contract specifications.

The questions asked by contractors may make it necessary to alter the documents they have received. However, there may be other reasons for introducing alterations by the orderer. According to the PPL, if, as the result of changing the specifications of the vital conditions of the contract not leading to the change in the call for tenders, the contractors need more time to alter their bids, the orderer postpones the deadline for submitting bids and informs them about it. In the case of changing the call for tenders, the orderer, if necessary, may postpone the deadline for submitting requests for participation in the bid or the deadline for submitting bids for as long as it is necessary to change the requests or bids. If the alteration is significant and, in particular, refers to the specification of the subject, size or range of the order, criteria or evaluation of the bids, conditions of participation or the way of evaluating how the conditions are fulfilled, the orderer must delay the deadline for submitting requests for participation in the procedure or the deadline for submitting bids for the time necessary to introduce changes in the requests or bids.

The orderer evaluates the bids according to the rules and criteria included in the specifications of the vital conditions of the contract. In special cases, though, the PPL allows to cancel the procedure. This may happen, for example, when the price of the most beneficial bid or the bid with the lowest price is higher than the price that the orderer intends to pay for the investment.

\section{Description of the subject of the building works procurement}

Appropriately prepared bid documents describing the subject of the order are the fundamental issue. They should be supplied in accordance with the requirements specified in articles 29-31 PPL and indicate to the contractor not only the subject matter of the future service but also all the conditions and 
circumstances in which the service will be performed. As the PPL requires, when preparing a public procurement award procedure, the orderer also has to prepare a document on significant terms and conditions of the tender.

It has to be emphasized that public procurement is understood as ordering both completing and, jointly, designing and performing building works. In the case of procurement of building works, the subject of the contract is described by means of design documentation and technical specifications for performance and acceptance of works. The scope of design documentation depends on, among others, the form of the payment for the contractor. In the case of fixed remuneration, the orderer does not have to give the bill of quantities to the contractor, and if he/she already did so, he/she cannot require the contractor to calculate on this basis the estimated price. If the subject of the procurement is designing and performing building works (Kosecki, 2003) as it is understood in the Act of 7 th July 1994 - Construction Law, the orderer describes the subject of the procurement by means of a functional-utility program (Minister of Infrastructure's Regulation of 2 September 2004 on the scope and form of the design documentation, technical specifications, performance and acceptance of the works and the functional-utility program).

According to article $29 \mathrm{PPL}$, the orderer describes the subject of the procurement in an explicit and exhaustive way using precise and comprehensible language, accounting for all requirements and circumstances that can influence bid preparation. Thus the orderer should ensure such a description of the subject of procurement that there arise no doubts or additional interpretations of what building works might be the subject of the future performance. The orderer should also provide all the requirements and circumstances which may influence bid preparation, such as conditions in which building works will be performed, requirements concerning guarantee on the subject of procurement: its scope and liability period, the place of completing the service, additional services associated with the principal works, etc. (Niemczyk).

To specify the subject of procurement the orderer is obliged to use standard technical terminology which is typically associated with a given business and is comprehensible to the future contractors.

The Act also points to the fact that the subject of procurement cannot be described in a way that hinders fair competition (art. 29 paragraph 2). The subject of procurement cannot be described by trademarks, patents or origin unless the specificity of the subject of procurement makes it necessary to do so, as the orderer cannot describe the subject by means of such precise terms; instead, this recommendation should be accompanied by the expression "or equivalent".

\section{Description of the analysed procedures and questions}

In order to understand problems with preparing a bid, the results of a number of instances of building works procurement announced by the authorities of chosen cities in the years 2010-2011 were analyzed. Table 1 presents the data studied.
The analysis comprised 268 procedures in total. It has to be noted that not all procedures provided all necessary data, therefore their number in the following more detailed analyses differs. The study embraces only open tender procedures. The majority concerned completion of building works while only 17 cases (6.34\%) required both designing and completion of works. There were on average 5.55 bids per procedure (the least: 1 bid, the most: 19).

In $53 \%$ of all procedures no question was asked. The maximal number of questions was 348, which were asked in a procedure done in Katowice. Table 2 presents a more detailed description of procedures in individual cities.

In four of the six cities under investigation the greatest number of questions was higher than 100, which, taking into consideration time necessary to prepare answers, can be considered a lot. Procedures with the greatest number of questions asked by contractors concerned various types of works, but most of them were investments of significant value, whose design was unusual (e.g. the sewage treatment plant or stadium). Two cases involved works in the $d \& b$ system, which seems understandable, as the contractor designs and then completes the investment according to the design, which may lead to numerous doubts about the

\begin{tabular}{|l|c|}
\hline \multicolumn{1}{|c|}{ City } & $\begin{array}{c}\text { Number of procedures analyzed } \\
(\mathbf{2 0 1 0 - 2 0 1 1 )}\end{array}$ \\
\hline Piotrków Trybunalski & 65 \\
\hline Katowice & 64 \\
\hline Rzeszów & 19 \\
\hline tódź & 28 \\
\hline Kraków & 12 \\
\hline Szczecin & 80 \\
\hline
\end{tabular}

Table 1 The analysis of procedures 


\begin{tabular}{|l|c|c|c|c|}
\hline \multicolumn{1}{|c|}{ City } & $\begin{array}{c}\text { No. of no } \\
\text { question } \\
\text { procedures (\%) }\end{array}$ & $\begin{array}{c}\text { Max no. of } \\
\text { questions }\end{array}$ & $\begin{array}{c}\text { Type of procurement with } \\
\text { max no. of questions }\end{array}$ & $\begin{array}{c}\text { Features of procurement with } \\
\text { max no. of questions }\end{array}$ \\
\hline $\begin{array}{l}\text { Piotrków } \\
\text { Trybunalski }\end{array}$ & $41(63 \%)$ & 134 & Sewage treatment plant & $\begin{array}{l}\text { Done in the d\&b system, postponed bid } \\
\text { submission deadline }\end{array}$ \\
\hline Katowice & $27(42 \%)$ & 348 & Road works & Postponed bid submission deadline \\
\hline Rzeszów & $10(53 \%)$ & 21 & Installation works & - \\
\hline tódź & $22(78 \%)$ & 300 & Sports stadium & Done in the d\&b system \\
\hline Kraków & $2(17 \%)$ & 31 & Building reconstruction & $\begin{array}{l}\text { Procedure with a postponed bid submission } \\
\text { deadline, estimate remuneration }\end{array}$ \\
\hline Szczecin & $40(50 \%)$ & 152 & Road works & Postponed bid submission deadline \\
\hline
\end{tabular}

Table 2 Procedure description

investor's expectations. In four cases it was necessary to postpone the deadline for bid submission.

In Krakow the greatest number of questions appeared in the procedure for which estimate remuneration was proposed. In this case the basis of the bid costs calculations was the bill of quantities provided by the orderer. Therefore, in the procedure under analysis the greatest number of questions concerned the bill of quantities itself and the incompatibility between the bill and other documents describing the subject of the order. It is true that in the case of the estimate remuneration the orderer does not take consequences of errors in the bill of quantities, but at the same time he/she cannot introduce any alterations to it. Thus when contractors wanted to calculate the real value of remuneration, they had to clarify all the ambiguities and discrepancies in the documents concerning the quantity of works.

Figure 1 presents the structure of the questions asked. The analysis included the procedures carried out in Krakow and Szczecin (270 questions in total).

The majority of questions concerned design documentation ( $41 \%$ of questions). Quite a number of them inquired about the building materials to be

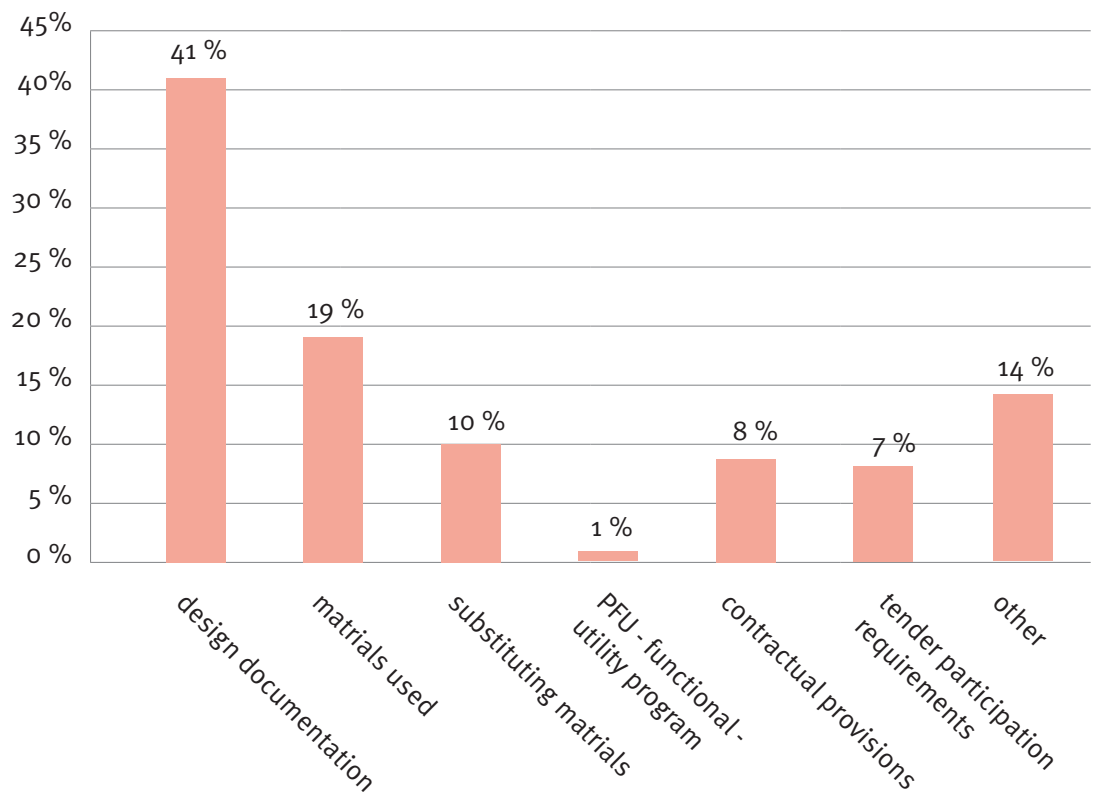

Figure 1 The structure of the questions asked (procedures performed by the City Council of Krakow and Szczecin)

used. There were requests for a more precise formulation of the orderer's requirements for materials, as well as inquires about possibilities of using substitutes. $1 \%$ of questions concerned the functional-utility program. Relatively little doubts were raised by the tender participation requirements or contractual provisions. Other questions included ones about guarantee conditions, postponing the deadline for bid submission, possibilities of site inspection, requests for the conditions of the journey to the construction site or for showing the location of contractor's temporary plant and facilities and the location of ground storage sites. The questions also related to delivering samples and taking into consideration VAT changes.

Since the greatest number of questions referred to design documenta- 


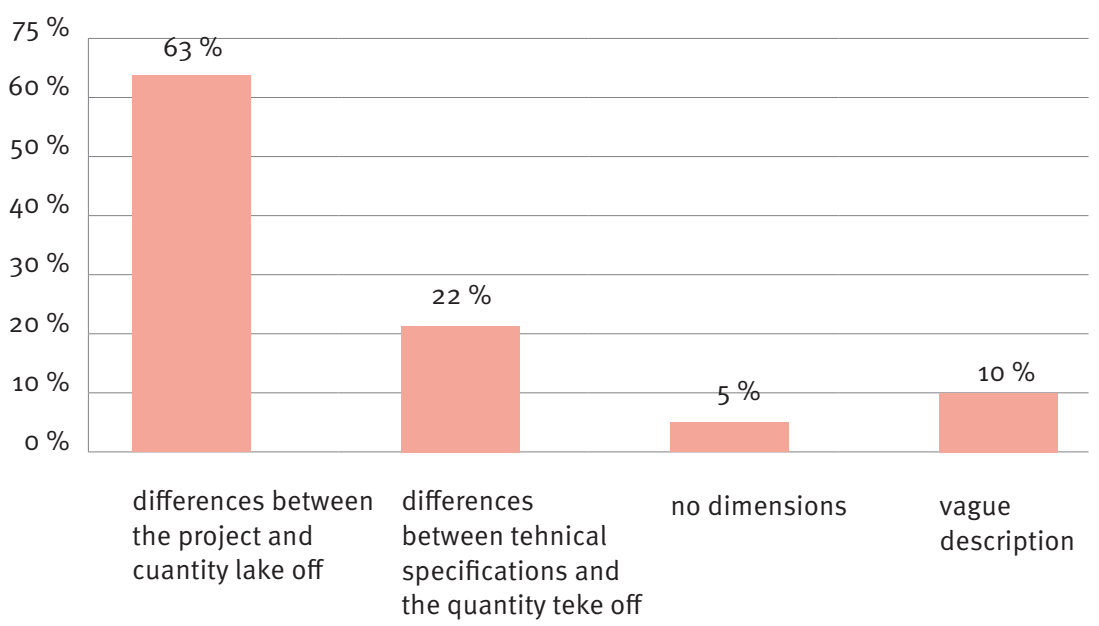

Figure 2 The structure of questions concerning design documentation

tion, Figure 2 depicts the scope of contractors' most frequent doubts related to the project.

The most doubts concerning design documentation arose in relation to the differences between the project and the quantity take off. Bidders also noticed that technical specifications and the project varied. In some cases the lack of dimensions in design documentation made appropriate cost calculation impossible and caused doubts as to whether certain elements were to be considered in calculations. What was noticed as well was the lack of an entry in the bill of quantities, of certain technical specifications, or incomplete information in the final design.



Figure 3 The number of procedures in which changes in the documentation were introduced, procedures were cancelled and the deadline for bid submission was postponed
In about $31 \%$ of all procedures documentation was changed or missing information was added. Let us remind that the procedures analyzed here were only these in which questions were asked, i.e. $90 \%$ of all collected for this study. This means that contractors' questions almost always lead to changes. A possible conclusion is that the questions were justified. The changes in bid documentation included completing bills of quantities, additional drawings, changing and completing technical specifications, changing and completing the significant terms and conditions of the tender, as well as changing and completing contractual provisions.

In $8 \%$ of cases a procedure was cancelled due to the fact that the lowest bid price tendered was higher than the value which the investor could pay for the contract. This is the evidence of the orderer's incorrect calculation of the value of the investment, the reason for which typically lies in the incomplete or badly prepared design documentation. It has to be noted that in the majority of public procurement the costs calculated by the orderer are normally higher than the costs tendered by contractors.

The results of the analysis proved the validity of contractors' questions signifying that bid documentation provided by the orderer may be lacking. It is possible then to assume that the number of questions asked by contractors is associated to a large extent with the quality of the documentation prepared.

The following analyses investigated the connection between the number of questions and procedure parameters.

\section{Number of questions and tender parameters}

The type of works ordered and the number of questions

In order to analyze how the type of building works influence the number of questions, 142 procedures in total were studied. Only these procedures 


\begin{tabular}{|l|c|c|c|c|}
\hline \multicolumn{1}{|c|}{ Type of works } & $\begin{array}{c}\text { No. of procedures } \\
\text { analyzed }\end{array}$ & Mean & $\begin{array}{c}\text { Max no. of } \\
\text { questions }\end{array}$ \\
\hline General investment works & 8 & 80,5 & 34,5 & 264 \\
\hline Engineering works & 9 & 66 & 8 & 330 \\
\hline Building renovation and modernization & 40 & 33 & 11,5 & 348 \\
\hline Road works & 55 & 27,46 & 5 & 146 \\
\hline Installation works & 30 & 7,75 & 1,5 & 47 \\
\hline
\end{tabular}

Table 3 The relation between the type of works ordered and the number of questions

were chosen in which the type of works could be unambiguously categorized as belonging to one of the following groups: general investment construction, engineering works, building renovation and modernization, road works, installation works. The results are shown by Table 3.

The greatest number of questions was asked for road works (348). However, taking into consideration the mean and median numbers, the most inquires arose for general investment constructions, in which a new building or a group of buildings is constructed. A considerable number of questions appeared for engineering works. The least were asked in the case of installation works.

The number of bids and the number of questions

To analyze the influence of the number of bids on the number of questions, 224 procedures in total were studied. Figure 4 depicts the relation between the number of bids and the number of questions, and the trendline.

Figure 4 leads to the conclusion that the greater number of bids there is, the greater number of questions arise. However, Pearson's correlation coefficient calculated for the data in Figure 4 is 0.35 which indicates weak correlation. The trendline suggests that every increase by one bidder causes an increase by 5 questions on average. Thus where there are 2 bids, there are 2 questions on average and where there are 10 bidders, there are 44 questions. Yet the weak correlation of data should make such predictions less reliable.

The value of the order and the number of questions

As many as 115 procedures were analyzed to study the influence of a contract value on the number of questions.

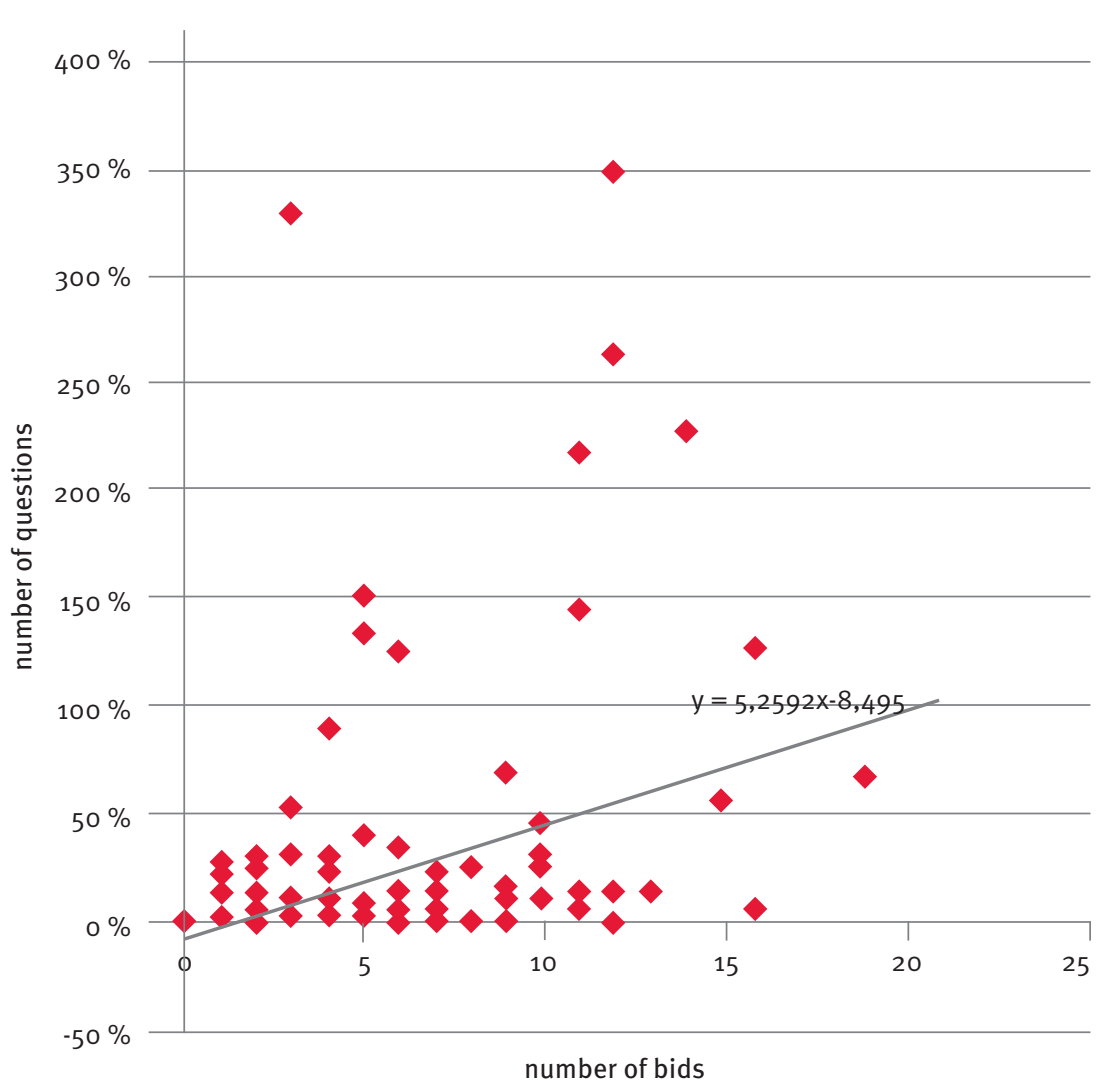

Figure 4 The relationship between the number of bids and the number of questions
Considering the price of the winning bid, 7 bid price ranges were adopted. The results are presented in Table 4.

The data in Table 4 indicate a strong relationship between the number of questions asked and the value of the order: the increase in its value clearly leads to the increase in the number of questions. The correlation coefficient is 0,7 proving the strong relation. 


\begin{tabular}{|c|c|c|c|}
\hline Price & No. of procedures & Mean no. of questions & $\begin{array}{l}\text { Median no. of } \\
\text { questions }\end{array}$ \\
\hline to $40000 \mathrm{PLN}$ & 13 & 0,77 & 0 \\
\hline $40000-100000$ & 7 & 1,71 & 0 \\
\hline $100000-500000$ & 35 & 2,34 & 0 \\
\hline $500000-1000000$ & 15 & 3,27 & 1 \\
\hline $1000000-10000000$ & 34 & 16,71 & 3.5 \\
\hline $10000000-50000000$ & 7 & 100,43 & 47 \\
\hline over 50000000 & 4 & 203,75 & 241,50 \\
\hline
\end{tabular}

Table 4 The relation between the order value and the number of questions

\section{Cause and effect of contractors' questions}

The analysis of questions that orderers are asked allows to specify the mistakes which can be found in the description of the subject of the order for building works. The most frequent mistakes include:

A vague description of the subject of the order, describing the subject in an ambiguous and incomplete way, using terms not clear or understandable enough, or not including all necessary requirements and circumstances which may influence the preparation of the bid.

Incomplete design documentation, e.g. no final design, technical specifications for work accomplishment and acceptance, or drawings.

Mistakes in design documentation and in technical specifications for work accomplishment and acceptance (Leśniak and Plebankiewicz, 2010).

Differences in the design, technical specifications and bill of quantities.

Using trademarks without allowing equivalent offers.

Imprecise definitions of goods equivalence, ambiguous and vague formulation of equivalence criteria.

The way the subject of the order should be described is clearly specified in the regulation; also technical specifications are an obligatory document which has to be prepared irrespective of the value or the scope of the order. Although mistakes and inaccuracies often result from the fact that these documents are prepared by different designers, it must be remembered that the responsibility for their appropriate preparation is solely the orderer's. Yet sometimes questions reveal contractors' ignorance, e.g. requesting that the orderer provides them with the bill of quantities or asking for changes in the bill of quantities in the case of fixed remuneration. In the latter situation the orderer does not have to provide the bill of quantities. The significant terms and conditions of the tender should clearly indicate that they only serve as a support and approximation, therefore the price has to be calculated on the basis of design documentation and technical specifications. Contractors' inquires may also be caused by their somewhat non-committal attitude in situations when the orderer's description causes doubts about the form of payment.

Questions regarding materials used, elements and alternate technologies arise when the materials or solutions adopted in the documentation are hard to be acquired by the contractor or when they are too expensive but it is possible to replace them with equivalents that are easier to obtain and are cheaper. In specifications the orderer should include a record of what equiva- lent materials and solutions can be used on condition that they guarantee the completion of works in accordance with the building permit and that the technical parameters will be no worse than the ones assumed in the documentation and in the specifications for work accomplishment and acceptance.

On the whole, the reasons for questions and doubts can be traced in both orderer's and contractors' lapses. Orderers frequently fail to share files necessary to prepare a bid properly, or they use contradictory specifications. Unfortunately, they often cannot ensure coherence and completeness of the documentation given to contractors. As a consequence, such documentation has to be later completed by engineering drawings and bills of quantities, which in turn requires collecting additional resources by the orderer in order to prepare answers to the questions and to introduce the necessary improvements to the documents.

Lapses on the part of the contractor include inaccurate reading of documentation. This often results from the fact that bidders learn about the procedure late and do not have enough time to carefully analyze the orderer's requirements. In extreme cases the need to postpone the bid submission deadline may cause problems for both the contractor and the orderer. 


\section{CONCLUSIONS}

Properly prepared documentation given to contractors in the bidding procedure is the necessary condition for them to submit bids that fulfill the orderer's requirements. The article analyzes a number of public procurement procedures. In almost half of them the bidders had no questions, yet in some of the remaining ones the bidders asked more than a hundred. Guilt is not always on the part of the orderer, but the fact that the majority of questions concerns design documentation including contradictions in its individual elements, and that questions make it necessary to introduce changes by the orderer, indicate its faulty preparation. If document preparation is entrusted to reliable designers, the orderer will avoid devoting time and resources to introduce improvements. On the other hand, contractors' careful reading of documentation and their familiarity with the regulations concerning public procurement may decrease the number of, unnecessary at times, questions.

The analyses performed here proved the relation between the number of questions asked and the type of works, the value of the contract and the number of bids. It was demonstrated that on average the greatest number of questions was asked for general investment constructions and engineering works. The smallest number of questions was asked for installation works. The analyses show a strong relation between the number of questions and the value of the contract: the increase in the contract value is accompanied by the increase in the number of questions. Likewise, the larger the number of bids, the larger the number of questions, yet in this case the correlation is much weaker. The trendline leads to the conclusion that each increase by one bidder increases the number of questions by 5 on average.

Knowing the factors influencing the number of questions and the condition- ings for each contract, the orderer may, to some extent, predict the probability of introducing changes to their documentation or prolonging the deadline for bid submission.

\section{References}

Kosecki, A. (2003), "Zarządzanie

przedsięwzięciem budowlanym jako ustuga regulowana umową, cz.l” [,Managing the construction project as a contract-regulated service, part I"], Przegląd Budowlany, 3, pp.36-39- in Polish.

Leśniak, A. and Plebankiewicz, E. (2010), "Błędy w specyfikacjach technicznych wykonania i odbioru robót budowlanych" ["Errors in technical specifications of application and acceptance of building works"], Czasopismo Techniczne, 1-B, 2, pp. 249-257 - in Polish.

Minister of Infrastructure's Regulation of 2 September 2004 on the scope and form of the design documentation, technical specifications, performance and acceptance of the works and the functional-utility program (Journal of Laws No. 202 pos. 2072), as amended (Journal of Laws No. 75 , pos. 2075 of 22nd April 2005, No. 72, pos. 464 of 23 rd April 2010 and No. 42, pos. 217 of 18th February 2011).

Niemczyk, R., „Opis przedmiotu zamówienia w praktyce". ["The description of the order subject in practice"] http://www.orgbud.pl/ serwis/aktual/artykul88.php - in Polish.

The Act of 29th January 2004 Public Procurement Law Journal of. Laws of 2010 No. 113, pos. 759 and No. 161, pos. 1078 , as amended). 